\title{
Article \\ Effect of Cooling Rate on the Microstructure Evolution and Mechanical Properties of Iron-Rich Al-Si Alloy
}

\author{
Xiao Shen ${ }^{1}$, Shuiqing Liu ${ }^{1,2, *}$, Xin Wang ${ }^{3, *}{ }^{\oplus}$, Chunxiang Cui ${ }^{3}$, Pan Gong ${ }^{4}{ }^{\circ}$, Lichen Zhao ${ }^{3}$, Xu Han ${ }^{1,2}$ \\ and Zirui $\mathrm{Li}^{1}$
}

check for updates

Citation: Shen, X.; Liu, S.; Wang, X.; Cui, C.; Gong, P.; Zhao, L.; Han, X.; $\mathrm{Li}, \mathrm{Z}$. Effect of Cooling Rate on the Microstructure Evolution and Mechanical Properties of Iron-Rich Al-Si Alloy. Materials 2022, 15, 411. https://doi.org/10.3390/ma15020411

Academic Editor: Amir Mostafaei

Received: 29 November 2021

Accepted: 4 January 2022

Published: 6 January 2022

Publisher's Note: MDPI stays neutral with regard to jurisdictional claims in published maps and institutional affiliations.

Copyright: (C) 2022 by the authors. Licensee MDPI, Basel, Switzerland. This article is an open access article distributed under the terms and conditions of the Creative Commons Attribution (CC BY) license (https:// creativecommons.org/licenses/by/ $4.0 /)$.
1 School of Mechanical Engineering, Hebei University of Technology, Tianjin 300401, China; sx961216@163.com (X.S.); xhan@hebut.edu.cn (X.H.); lizirui@gmail.com (Z.L.)

2 State Key Laboratory for Reliability and Intelligence of Electrical Equipment, School of Materials Science and Engineering, Hebei University of Technology, Tianjin 300401, China

3 Key Laboratory for New Type of Functional Materials in Hebei Province, School of Materials Science and Engineering, Hebei University of Technology, Tianjin 300401, China; hutcui@hebut.edu.cn (C.C.); zhlch@hebut.edu.cn (L.Z.)

4 State Key Laboratory of Materials Processing and Die \& Mould Technology, School of Materials Science and Engineering, Huazhong University of Science and Technology, Wuhan 430074, China; pangong@hust.edu.cn

* Correspondence: sqliu@hebut.edu.cn (S.L.); ahaxin@hebut.edu.cn (X.W.)

\begin{abstract}
The mechanical properties of iron-rich Al-Si alloy is limited by the existence of plenty of the iron-rich phase $\left(\beta-\mathrm{Al}_{5} \mathrm{FeSi}\right)$, whose unfavorable morphology not only splits the matrix but also causes both stress concentration and interface mismatch with the Al matrix. The effect of the cooling rate on the tensile properties of Fe-rich $\mathrm{Al}-\mathrm{Si}$ alloy was studied by the melt spinning method at different rotating speeds. At the traditional casting cooling rate of $\sim 10 \mathrm{~K} / \mathrm{s}$, the size of the needle-like $\beta-\mathrm{Al}_{5} \mathrm{FeSi}$ phase is about $80 \mu \mathrm{m}$. In contrast, the size of the $\beta-\mathrm{Al}_{5} \mathrm{FeSi}$ phase is reduced to $500 \mathrm{~nm}$ and the morphology changes to a granular morphology with the high cooling rate of $\sim 10^{4} \mathrm{~K} / \mathrm{s}$. With the increase of the cooling rate, the morphology of the $\beta-\mathrm{Al}_{5} \mathrm{FeSi}$ phase is optimized, meanwhile the tensile properties of Fe-rich Al-Si alloy are greatly improved. The improved tensile properties of the Fe-rich Al-Si alloy is attributed to the combination of Fe-rich reinforced particles and the granular silicon phase provided by the high cooling rate of the melt spinning method.
\end{abstract}

Keywords: Fe-rich $\mathrm{Al}-\mathrm{Si}$ alloy; $\beta-\mathrm{Al}_{5} \mathrm{FeSi}$ phase; cooling rate; melt spinning; microstructure; strengthening mechanisms

\section{Introduction}

Recycled aluminum is obtained through the recycling of waste aluminum products. The production energy consumption is only $3 \%$ to $5 \%$ of the energy consumption of primary aluminum [1]. It has obvious advantages in energy saving and emission reduction, thus it has become one of the research hotspots in the field of lightweight structural materials. Iron is considered to be the most harmful impurity element in recycled aluminum. The main reason is that the solid solubility of iron in cast aluminum-silicon alloy is low (only $0.05 \mathrm{wt} . \%$ ) and a variety of iron-rich intermetallics can be formed during solidification, such as $\alpha-\mathrm{AlFeSi}, \beta-\mathrm{Al}_{5} \mathrm{FeSi}, \pi-\mathrm{Al}_{8} \mathrm{Mg}_{3} \mathrm{FeSi}_{6}$, and $\delta-\mathrm{Al}_{4} \mathrm{FeSi}_{2}$. Among them, $\beta-\mathrm{Al}_{5} \mathrm{FeSi}$ is long and needle-like on the two-dimensional optical micrographs and the three-dimensional space is a lath structure [2-4].

The size and morphology of the secondary phase are the key factors affecting the properties of the alloy. The needle-like $\beta-\mathrm{Al}_{5} \mathrm{FeSi}$ phase is easy to cause stress concentration and split the matrix, which is unfavorable to the mechanical properties of recycled aluminum $[5,6]$. In addition, excessive iron content will lead to poor melt fluidity and reduce casting quality [7]. Therefore, many researchers are working to modify the morphology of $\beta-\mathrm{Al}_{5} \mathrm{FeSi}$ phases, such as by adding the alloying elements $\mathrm{Mn}, \mathrm{Nb}, \mathrm{Co}, \mathrm{Sc}, \mathrm{Er}$, etc. [8-12]. 
In addition, increasing the melt superheat and heat treatment are also effective ways to improve the morphology of the iron-rich phase. In our previous work, it was found that the combination addition of $\mathrm{Mg}$ and La elements can promote the transition from $\beta-\mathrm{Al}_{5} \mathrm{FeSi}$ to the script-like $\pi-\mathrm{Al}_{8} \mathrm{Mg}_{3} \mathrm{FeSi}_{6}$ phase, resulting in a $65 \%$ increase in the yield strength of $\mathrm{Al}-\mathrm{Si}-\mathrm{Mg}-\mathrm{Fe}$ alloy [13]. However, the addition of the above elements only changes the morphology of the iron-rich phase, brings some technical problems, and further increases the difficulty of the secondary resource recovery of Al-Si alloys. Therefore, it is a key issue to develop high performance Al-Si alloys with a high Fe content.

Increasing the cooling rate is an effective way to change the morphology of an intermetallic. Melt spinning is a typical rapid solidification method which is used in the preparation of inoculants due to its chemical uniformity and large solid solubility [14-16]. Additionally, the microstructure evolution has been reported to be dependent on the cooling rate and Fe content in the $\mathrm{Al}-\mathrm{Si}$ alloy $[17,18]$. The cooling rates range from 1 to $10 \mathrm{~K} / \mathrm{s}$ in traditional mold casting to $10 \mathrm{~K} / \mathrm{s}-100 \mathrm{~K} / \mathrm{s}$ in high-pressure die casting. It can be seen that the morphology control of the cooling rate on the $\beta-\mathrm{Al}_{5} \mathrm{FeSi}$ phase is generally limited to the sub-rapid solidification (cooling rates $<10^{3} \mathrm{~K} / \mathrm{s}$ ) condition and there is a need to explore the microstructure under the rapid solidification condition with cooling rates higher than $10^{3} \mathrm{~K} / \mathrm{s}$. Moreover, although some studies have analyzed the growth behavior and morphology of the needle-like $\beta-\mathrm{Al}_{5} \mathrm{FeSi}$ phases in specific recycled Al-Si alloy, a systematic way to understand the formation or suppression of the needle-like phase is not available.

In this work, we achieve different cooling rates by adjusting the speed of the copper roller during melt spinning. Through in-depth analysis of the phase microstructure morphology of $\beta-\mathrm{Al}_{5} \mathrm{FeSi}$ under different cooling rates, the solidification path and formation conditions are discussed. Meanwhile, the effect of the cooling rates on the microstructure and tensile properties using the rapid solidification technology is further investigated.

\section{Materials and Methods}

The Al-10Si-1.5Fe (all compositions cited in this work are in wt. \%) alloy investigated in this work was prepared from the as-cast ingots of commercial Al-12Si and Al-20Fe alloys, and its chemical composition is shown in Table 1. The raw and processed materials were melted in a vacuum arc furnace under an argon atmosphere. For a low cooling rate sample, the ingots were remelted by the induction smelting method, during which it was poured into the preheated $200{ }^{\circ} \mathrm{C}$ steel mold with a cavity diameter of $20 \mathrm{~mm}$ and a height of $120 \mathrm{~mm}$, which was denoted as the C1 alloy. For high cooling rate samples, secondary melting of intermediate alloy was carried out in a high-frequency induction smelting furnace and blown on a copper roller with a diameter of $22 \mathrm{~cm}$ and rotating speed of both $2000 \mathrm{rpm}$ and $4000 \mathrm{rpm}$ to produce Al-10Si-1.5Fe ribbons (abbreviated as C2 and C3 alloy, respectively). According to the results of the previous studies [19-23], the cooling rates were calculated as $6.7 \times 10^{2} \mathrm{~K} / \mathrm{s}, 2.4 \times 10^{4} \mathrm{~K} / \mathrm{s}$, respectively.

Table 1. Composition of the experimental alloy.

\begin{tabular}{ccccccc}
\hline Element & Al & Si & Fe & Mg & Cu & Zn \\
\hline Content & Balance & 9.96 & 1.52 & 0.33 & 0.09 & 0.07 \\
\hline
\end{tabular}

The specimens were cut from the middle of the casting rod and the spun ribbon for metallographic examination, and then were carefully ground by sandpaper in ethanol as well as dried with air. After mechanical polishing, the specimens were corroded by Poulton's reagent and observed by optical microscope. The microstructure of the samples was etched with $0.5 \%$ vol. HF solution before scanning electron microscope (SEM, Hitachi, Tokyo, Japan) observation. The chemical composition of the phases in the prepared alloys were examined by energy dispersive spectroscopy (EDS, Hitachi, Tokyo, Japan), which was performed on at least 3 parts of the phases. The tensile tests for the as-cast rods were 
carried out at a constant strain rate of $5 \times 10^{-4} \mathrm{~s}^{-1}$ and loaded parallel to the axis of the specimens following standard ASTM B209. Based on the same experimental scheme, the C2 and C3 ribbon samples were tensile-tested with a width of $2 \mathrm{~mm}$ and length of $120 \mathrm{~mm}$. Three tests were conducted for each sample condition. The samples were characterized by Bruker D8 Discover X-ray diffraction (XRD, Bruker AXS, Karlsruhe, Germany), Cu Ka radiation, the $\$ 4800$ scanning electron microscope (SEM, TESCAN, Czech Republic), Nova Nano SEM450 (SEM, FEI Company, Portland, America) and the optical microscope (OM, Olympus, Jiang dong ou yi testing instrument, Ningbo, China).

\section{Results and Discussion}

Figure 1 shows the typical XRD spectra of Al-10Si-1.5Fe alloys with different cooling rates. It can be seen that at the cooling rate of $\sim 30 \mathrm{~K} / \mathrm{s}$, the $\mathrm{C} 1$ alloy had three groups of sharp diffraction peaks corresponding to $\mathrm{Al}, \mathrm{Si}$, and $\beta-\mathrm{A} 15 \mathrm{FeSi}$ phases, respectively. It is clear that the $\delta-\mathrm{Al}_{3} \mathrm{FeSi}_{2}$ phase appeared in the $\mathrm{C} 2$ alloy with the cooling rate increase to $6.7 \times 10^{2} \mathrm{~K} / \mathrm{s}$. It is noteworthy that the iron-rich phase disappeared in the matrix as the cooling rate continued to increase to $2.4 \times 10^{4} \mathrm{~K} / \mathrm{s}$.
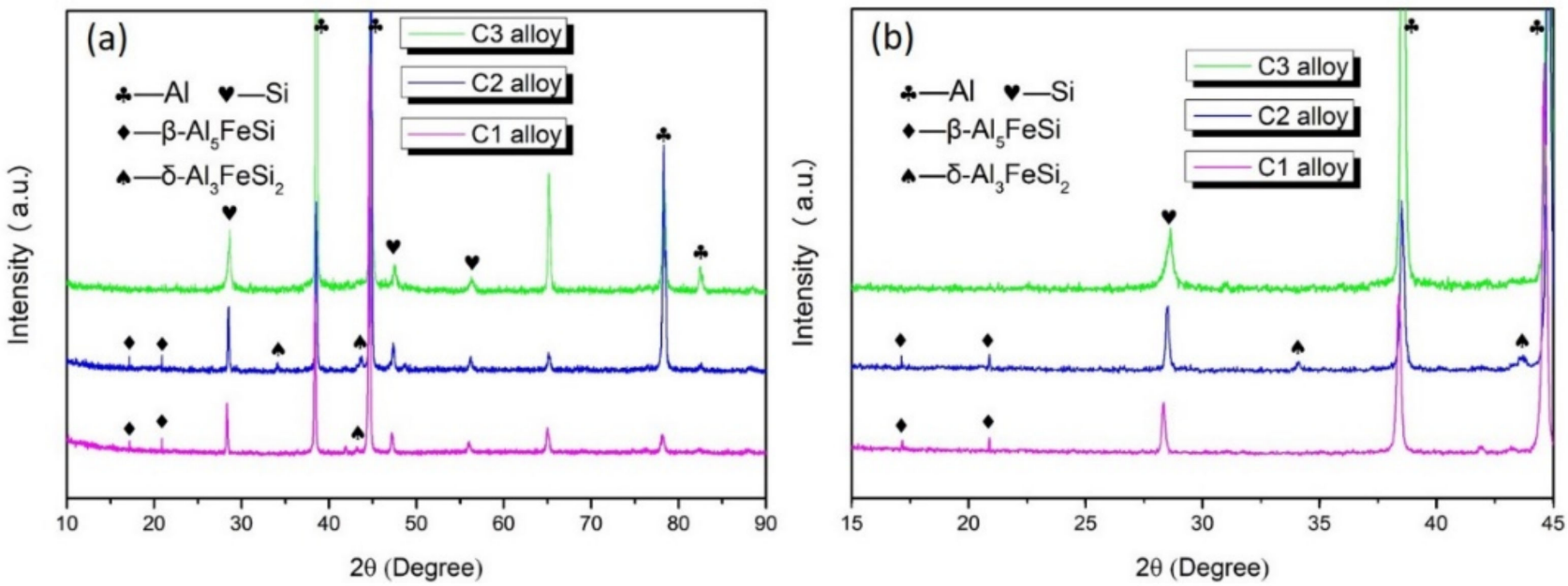

Figure 1. (a) XRD spectra of the $\mathrm{C} 1, \mathrm{C} 2$, and $\mathrm{C} 3$ alloys. (b) Shows the partially amplified spectra of (a).

Figure 2 shows the metallography of $\mathrm{Al}-\mathrm{Si}-\mathrm{Fe}$ alloy with different cooling rates. A large number of needle-like phases about $80 \mu \mathrm{m}$ in length and the acicular-like phase existed in the aluminum matrix. Take the XRD spectra into consideration; they are $\beta$ $\mathrm{Al}_{5} \mathrm{FeSi}$ phase and eutectic Si phase, respectively. It can be seen that the $\beta$-Al5FeSi phase was randomly distributed among the dendrites, as shown in Figure 2a, and its unfavorable morphology is particularly unfavorable to the strength and ductility of the matrix. It is noteworthy that the morphology of the Fe-rich phase in C2 changed significantly, that is, from needle-like to short rod-like with a length of $10 \mu \mathrm{m}$ with the increase of the cooling rate to $\sim 10^{2} \mathrm{~K} / \mathrm{s}$. In addition, increasing the cooling rate not only changes the morphology of the Fe-rich phase but also the eutectic Si phases transformed from coarse acicular-like to fine particle-like in the $\mathrm{C} 2$ alloy. As the cooling rate increased to $\sim 10^{4} \mathrm{~K} / \mathrm{s}$, the needle-like or fibrous phases were no longer visible in the field of view and a large number of dispersed particles were replaced, as shown in Figure 2e,f. Compared with the C1 and C2 alloy, the phases distributed in the C3 alloy matrix were more uniform and dispersed. 

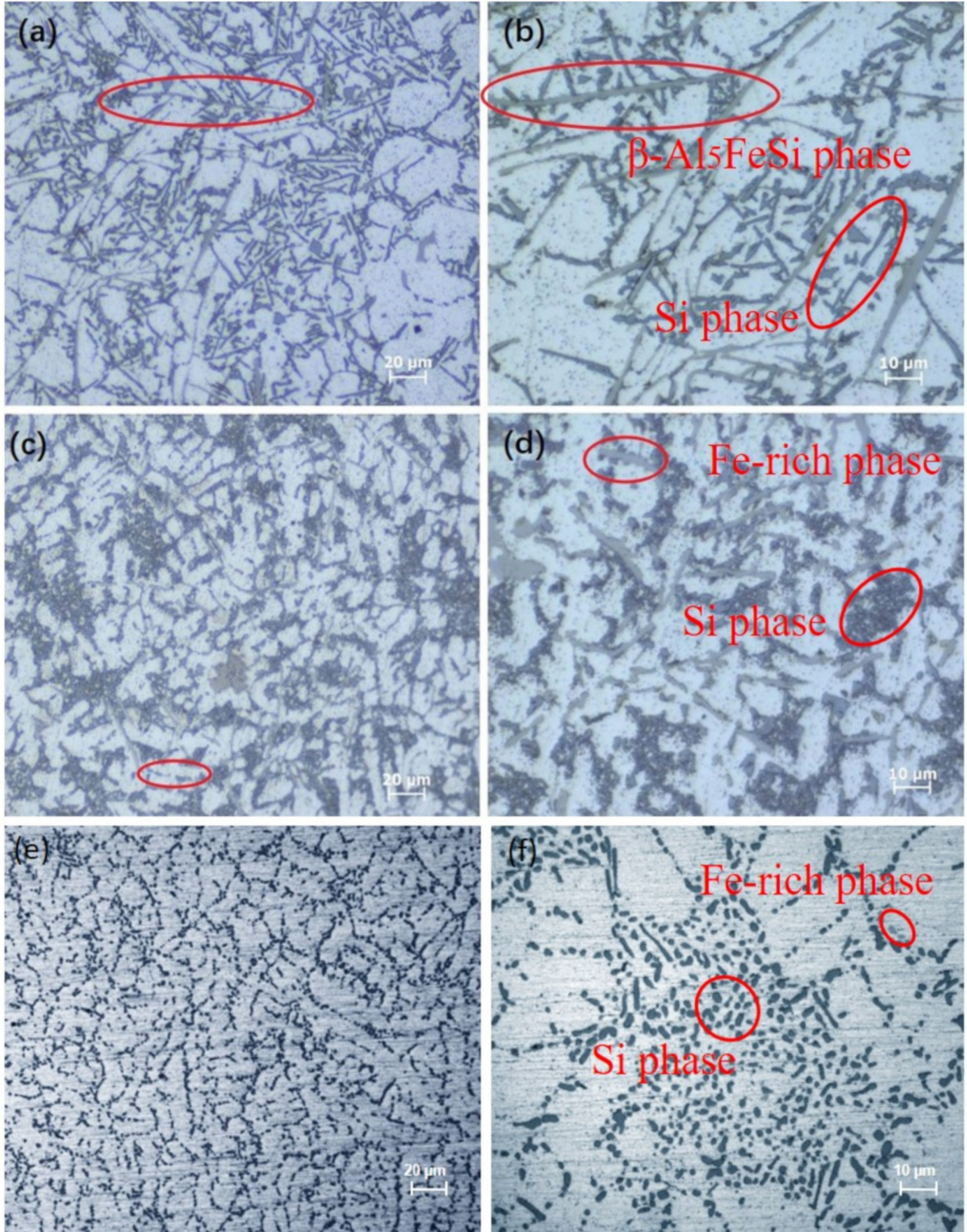

Figure 2. (a,c,e) are optical micrographs of $\mathrm{C} 1, \mathrm{C} 2$, and $\mathrm{C} 3$ alloy. (b,d,f) are optical micrographs showing locally amplified spectra of $(\mathbf{a}, \mathbf{c}, \mathbf{e})$, respectively.

Figure 3 shows the SEM images of Al-10Si-1.5Fe alloys at different cooling rates. Figure $3 a, c$ are the SEM images of the $\mathrm{C} 1$ and $\mathrm{C} 2$ samples, among which Figure $3 \mathrm{~b}, \mathrm{~d}$ are the local enlarged views of Figure $3 a, c$. In Figure $3 a, b$, the presence of long needle-like phases and sharp morphology in the die casting sample is more clearly observed than in Figure 3c-f. Combined with the EDS analysis in Figure 3e,f, the phase can be judged as $\beta-\mathrm{Al}_{5} \mathrm{FeSi}$. The comparison of Figure $3 \mathrm{a}, \mathrm{c}$ show that the Fe-rich phase transformed from a sharp long needle-like structure to a short rod-like morphology, wherein the distribution state was more diffuse and there was almost no obvious interweaving connection. Figure $3 \mathrm{~d}$ clearly shows that the short rod-shaped phase in the $\mathrm{C} 2$ alloy with the cooling rate of $6.7 \times 10^{2} \mathrm{~K} / \mathrm{s}$ was a fishbone-like shape, which can be determined as the $\delta-\mathrm{Al}_{3} \mathrm{FeSi}_{2}$ phase. The fishbone-like morphology phase had little effect on the fracture of the Al matrix, thus the mechanical properties of the matrix will be improved accordingly. Based on the above analysis, the increase in the cooling rate does have a regulatory effect on the morphology of the Fe-rich phase in the aluminum alloy. 

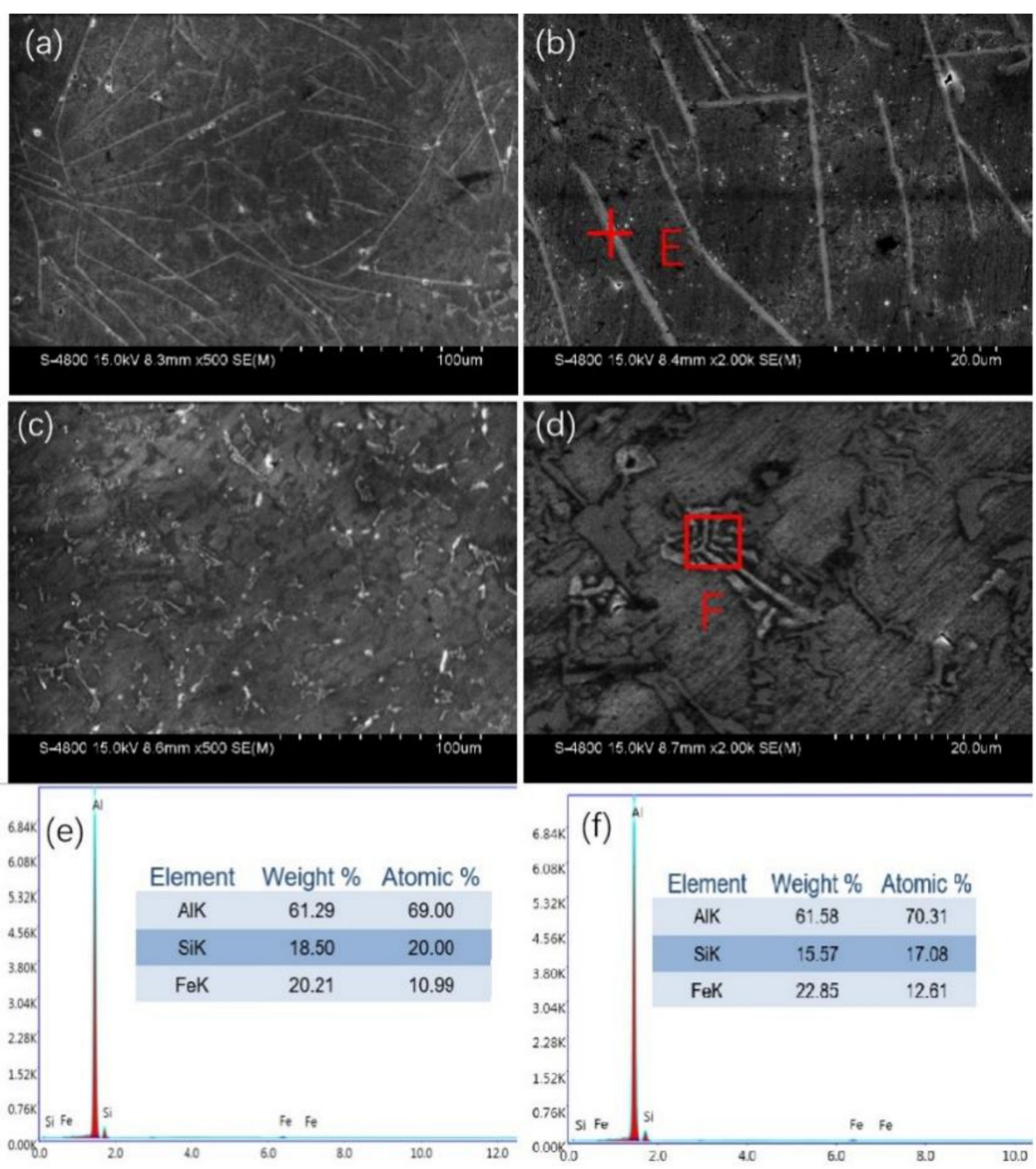

Figure 3. SEM images of the $(\mathbf{a}, \mathbf{b}) \mathrm{C} 1$ alloy and $(\mathbf{c}, \mathbf{d}) \mathrm{C} 2$ alloy. $(\mathbf{e}, \mathbf{f})$ are the EDS results of the $(\mathbf{b}, \mathbf{d})$ corresponding areas.

Figure 4 reveals the SEM images of the C3 alloy with the cooling rate of $2.4 \times 10^{4} \mathrm{~K} / \mathrm{s}$. It can be seen that two kinds of particles with different brightness were distributed in the matrix and the particle size ranged from $200 \mathrm{~nm}$ to $500 \mathrm{~nm}$. From the EDS inset in Figure 4b, it can be seen that the content of iron in this region was about $1 \mathrm{wt} . \%$, which is lower than the nominal composition of the Al-Si-Fe alloy. The cooling rate can obviously change the morphology of iron-rich phase because at a high cooling rate, Fe does not have enough time to precipitate in the form of the intermetallic phase. Instead, $\mathrm{Fe}$ is trapped in the $\mathrm{Al}$ matrix to form a supersaturated solid solution. In order to clearly describe the change of the Fe-rich phase size with the cooling rate, the particle length and width statistical distribution of the three alloys is shown in Figure 5. It can be seen that with the increase of the cooling rate, the length of the Fe-rich phase decreased sharply and the length and width tended to be consistent, which tends to form spherical particles. The change is beneficial to the improvement of the tensile properties of the Fe-rich $\mathrm{Al}$ alloy. 

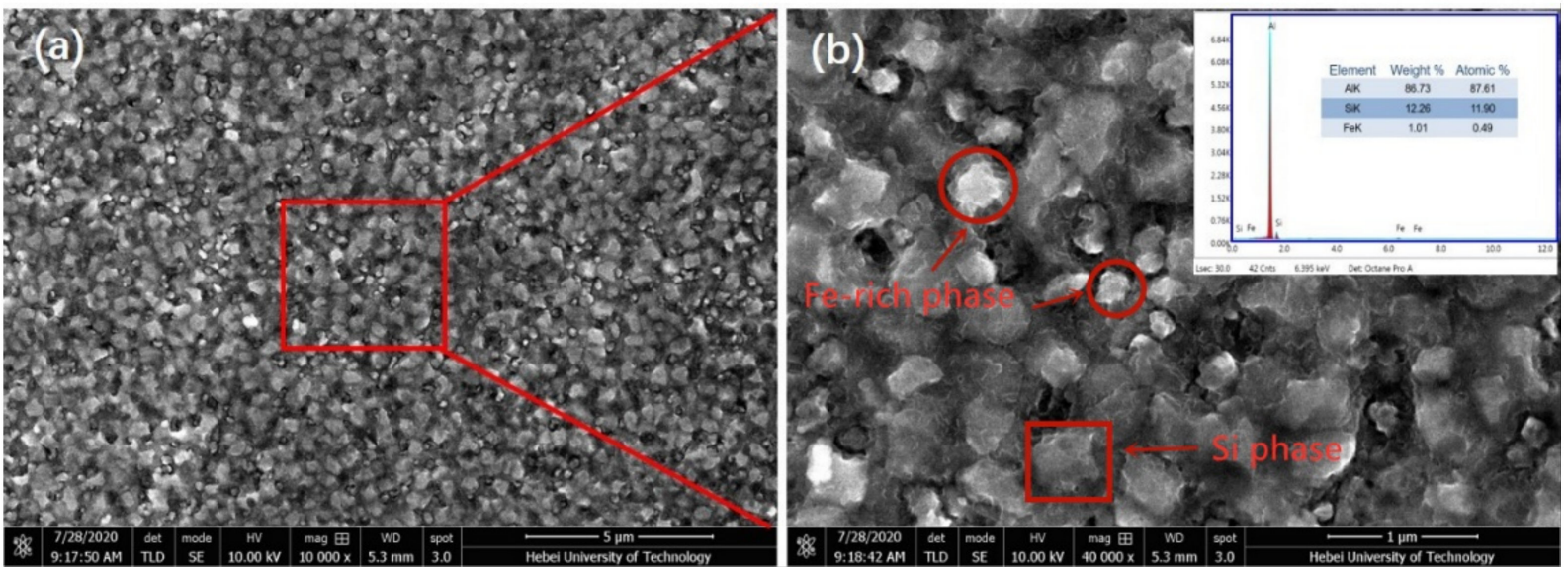

Figure 4. (a) SEM images of the C3 alloy. (b) is the magnification of the region in (a), while the inset is the EDS results of the region in (a).
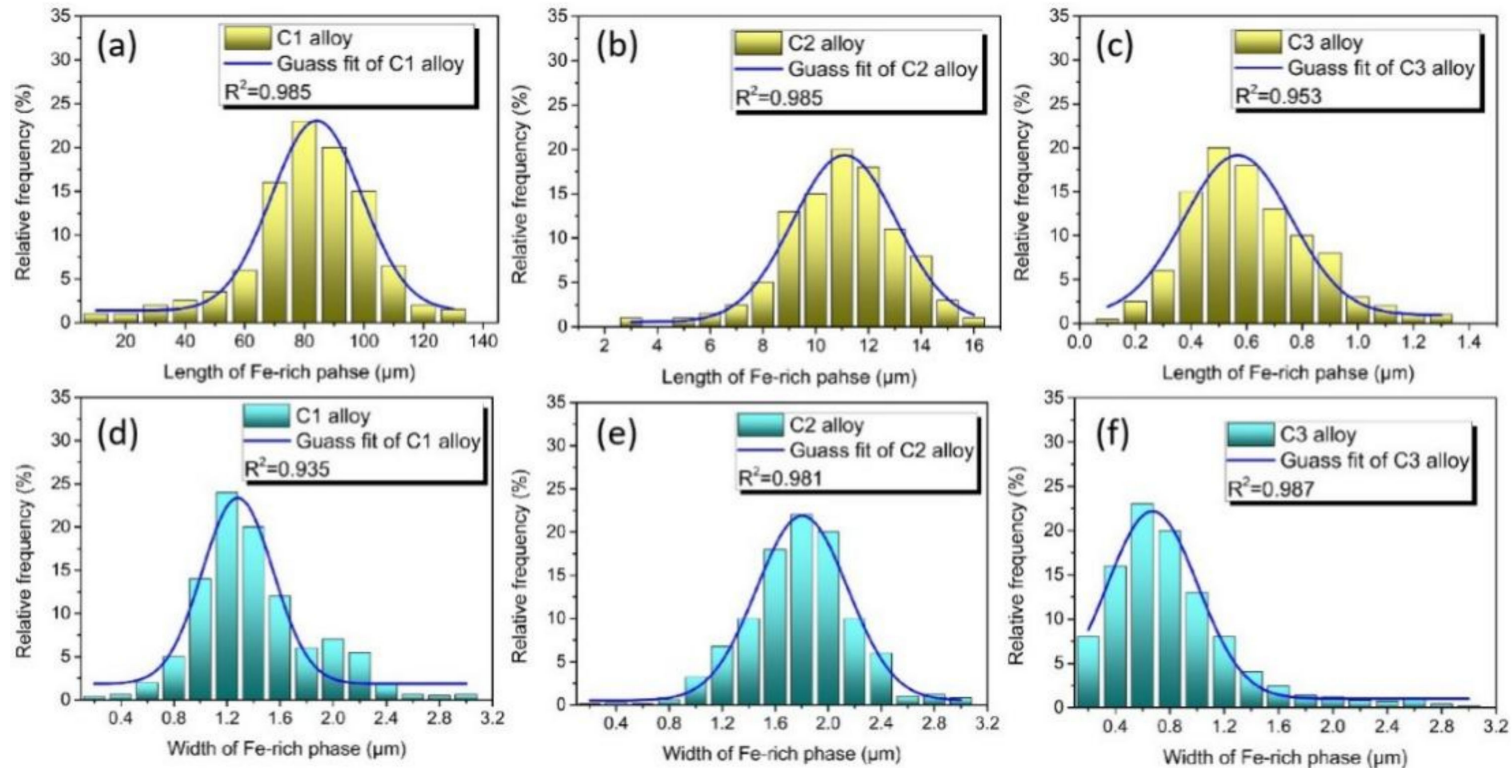

Figure 5. Statistical distribution of the length of Fe-rich phase of the (a) $\mathrm{C} 1$, (b) $\mathrm{C} 2$, and (c) C3 alloys, $(\mathbf{d}, \mathbf{e}, \mathbf{f})$ are the statistical distribution of the width of Fe-rich phase of the C1, C2 and C3 alloys, respectively.

Figure 6 reveals the Differential Thermal Analysis (DTA)curves of the alloy at different cooling rates, where the peak of the DTA curve represents the eutectic temperature of the alloy. As the cooling rate increased, the eutectic temperature gradually decreased from $577.2^{\circ} \mathrm{C}$ to $571.7^{\circ} \mathrm{C}$. According to the binary phase diagram of Al-Si alloy, the eutectic zone moves towards the non-metallic phase under the non-equilibrium solidification condition. The growth morphology of the silicon phase is not only restricted by the concentration distribution of the silicon atom at the growth interface but also is affected by the growth rate of $\alpha-\mathrm{Al}$. When the cooling rate is high, the $\alpha-\mathrm{Al}$ phase is the first to nucleate and grow during solidification, and silicon atoms are disposed to the front of the solid-liquid interface, which increases the concentration of the silicon element in liquid phase. At this time, the silicon phase changes its growth direction in staggered or twin mode. It can be seen that from the $\mathrm{C} 2$ and $\mathrm{C} 3$ alloys, they had a subtle derivative curve peak in the eutectic region corresponding to the formation of the $\delta-\mathrm{Al}_{3} \mathrm{FeSi}_{2}$ phase. That is, an increase in the cooling rate can promote the precipitate of the fishbone-like $\delta-\mathrm{Al}_{3} \mathrm{FeSi}_{2}$ phase to replace the harmful $\beta-\mathrm{Al}_{5} \mathrm{FeSi}$ phase. 

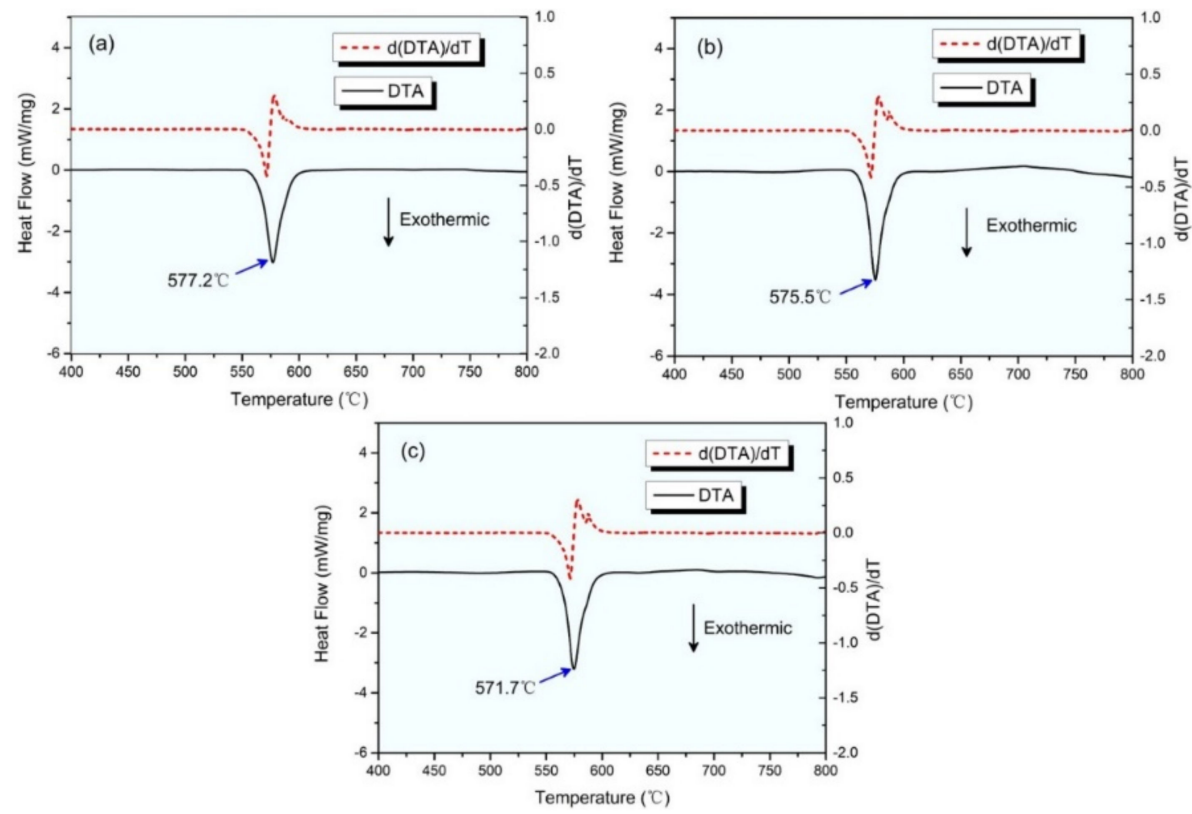

Figure 6. (a-c) DTA thermograph of C1 alloy, C2 alloy, and C3 alloy, respectively.

Figure 7 shows the tensile properties of the alloys with different cooling rates. As the cooling rates increased, the tensile strength and elongation of the alloys were significantly improved, as shown in Figure 7a. The quality index $Q$ can be expressed as follows [24]:

$$
\mathrm{Q}=\mathrm{UTS}(\mathrm{MPa})+150 \times \log (\% \mathrm{EI})
$$
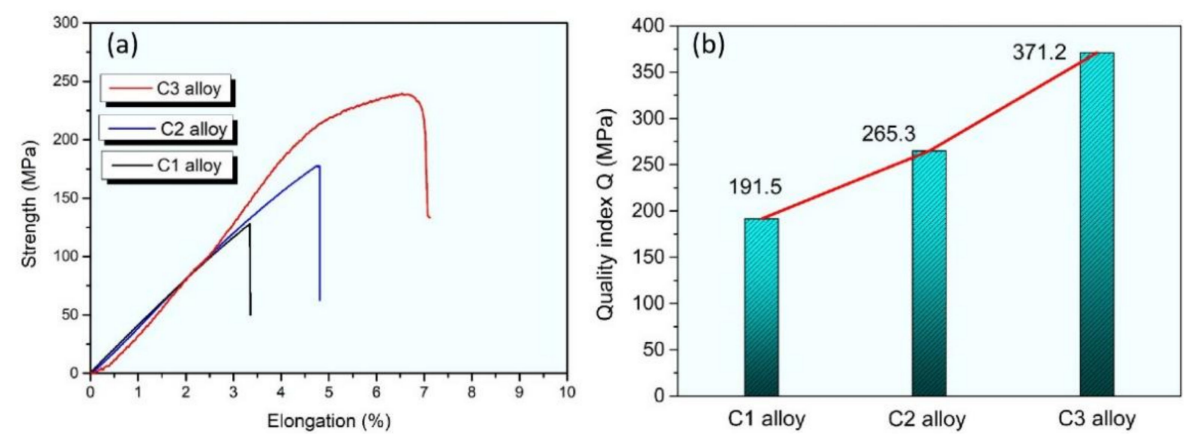

Figure 7. (a) Tensile properties of the alloys with different cooling rates. (b) The quality index Q of the three alloys.

Mass coefficient $Q$ includes both tensile strength (UTS) and elongation after fracture (EI), which is a more widely used and reliable parameter in engineering applications. As can be seen from Figure 7, there was no significant difference between the tensile properties of the $\mathrm{C} 2$ alloy and the as-cast $\mathrm{C} 1$ alloy, which is consistent with the results of Figures 2 and 3. The morphology of the needle-like $\beta$-phase did not change completely at the moderate cooling rate but the aspect ratio decreased. However, the tensile properties of the C 3 alloy with the high cooling rate are obviously improved compared with those of the $\mathrm{C} 1$ alloy and $\mathrm{C} 2$ alloy. It is mainly attributed to the transformation of the coarse needle-like $\beta$-phase into the $\delta-\mathrm{Al}_{3} \mathrm{FeSi}_{2}$ granular phase. In addition, the quality index of the $\mathrm{C} 3$ alloy is obviously higher than those of the other two alloys. The other main reason is that the acicular eutectic silicon phase transforms into fine fibers, which significantly reduces the stress concentration around the acicular silicon phase during the tensile process. As the cooling rates increased, this remarkably reduced the aspect ratio of the silicon phase. Overall, the strengthening mechanism is considered to be associated with the morphology change of the needle-like $\beta$-phase and with the decrease in aspect ratio of the eutectic silicon phase. The optimization 
of the phase morphology can significantly reduce the stress concentration and improve the load transfer capacity so as to inhibit the initiation and propagation of cracks during the tensile process [25-27].

In order to better understand the failure mechanism of the alloy at different cooling rates, fracture studies were carried out on each tensile fracture sample. Figure $8 \mathrm{a}, \mathrm{c}$ show the cleavage mode of the fracture with evidence of many brittle cleavage planes separated by tearing ridges. It can be observed in the high-magnification SEM fractography of Figure $8 \mathrm{a}, \mathrm{c}$ that coarse secondary phases caused the initiation and fast propagation of cracks. This can be responsible for the low elongation value of the alloys. The plastic deformation of $\alpha-\mathrm{Al}$ grains are inhibited because the dislocation cannot pass through the $\beta$ phase by the shear or bypass mechanism $[28,29]$. As a result, dislocations continue to accumulate at the interface between the $\beta$-phase and aluminum matrix and result in severe stress concentrations, which lead to a higher tendency of brittle fractures. The existence of these cleavage planes indicates that these alloys exhibit brittle fracture and need sufficient modification for practical applications. It is worth noting that the fracture mode of the $\mathrm{C} 3$ alloy was different from that of the $\mathrm{C} 1$ and $\mathrm{C} 2$ alloys, and a large number of dimples appeared on the fracture surface, as shown in Figure 8e,f. The ductile fracture was determined by the size of the dimples, meaning that more homogenous and deeper dimples produce a higher ductility of the alloys. The existence of deep and conical dimples in the C3 alloy shows the higher ductility, which is consistent with the results shown in Figure 7. The realization of better mechanical properties is attributed to the combined effect of the harmful morphology of the $\beta$ phase and to the spheroidization of the silicon phase.
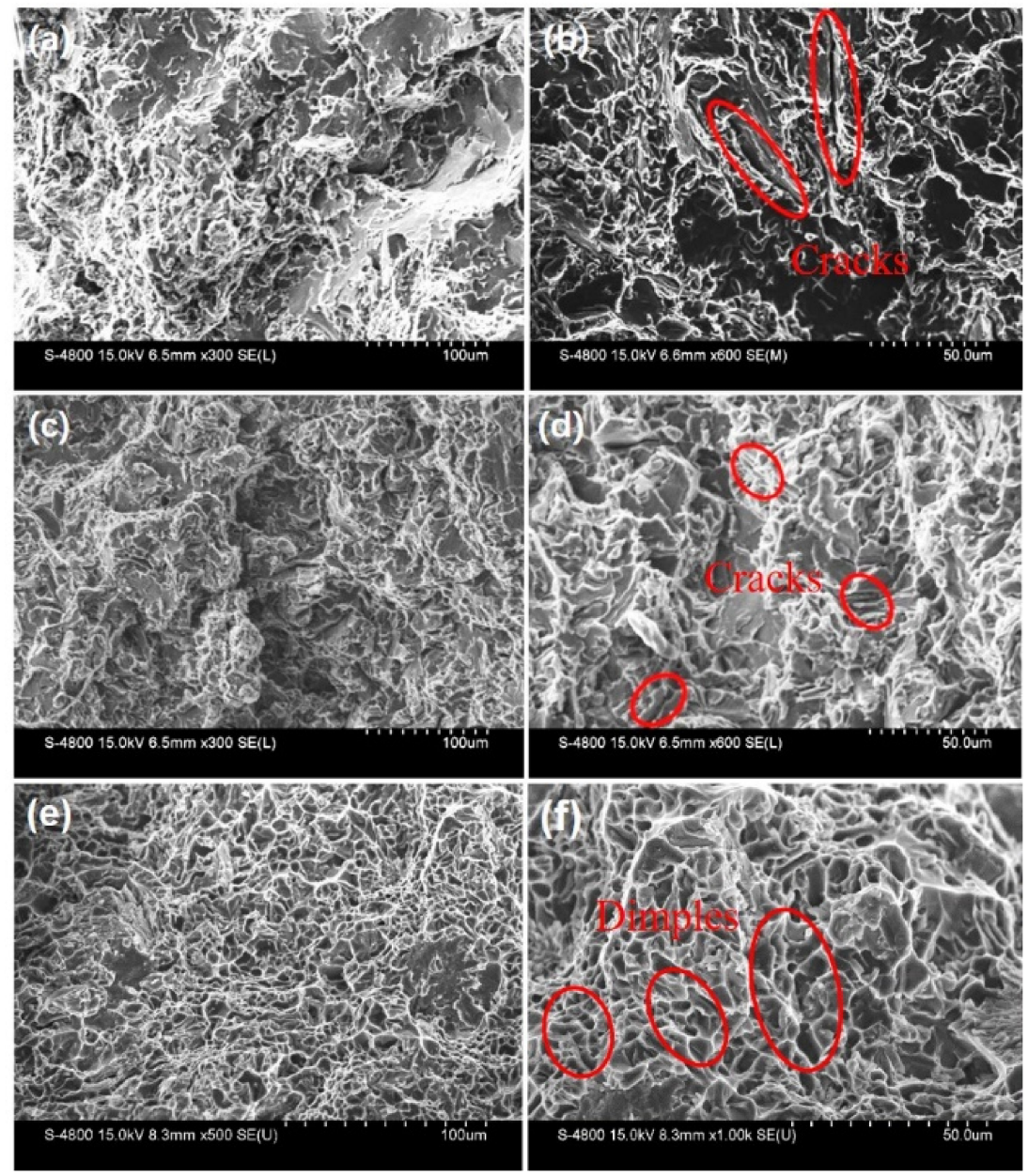

Figure 8. Fracture surface of the alloys with different cooling rates: $(\mathbf{a}, \mathbf{c}, \mathbf{e})$ represent $\mathrm{C} 1, \mathrm{C} 2$, and $\mathrm{C} 3$ alloy, respectively. $(\mathbf{b}, \mathbf{d}, \mathbf{f})$ are the enlarged images of the corresponding areas. 


\section{Conclusions}

(1) The morphology of the Fe-rich phase in Al-Si alloy is greatly affected by the cooling rate. The needle-like $\beta-\mathrm{Al}_{5} \mathrm{FeSi}$ phase had the size of $\sim 80 \mu \mathrm{m}$ at the conventional casting cooling rate. As the cooling rate increases to $\sim 10^{2} \mathrm{~K} / \mathrm{s}$, the needle-like $\beta$-phase changes into the fishbone-like $\delta-\mathrm{Al}_{3} \mathrm{FeSi}_{2}$ phase. At a high cooling rate of $\sim 10^{4} \mathrm{~K} / \mathrm{s}$, the size of the $\beta-\mathrm{Al}_{5} \mathrm{FeSi}$ phase decreases to $\sim 500 \mathrm{~nm}$ and the morphology changes to a granular form.

(2) The change of cooling rate reduces the eutectic temperature of Fe-rich Al-Si alloy and promotes the phase transformation of eutectic silicon. The DTA analysis results showed that the increase in the cooling rate contributes to forming the fishbone-like $\delta-\mathrm{Al}_{3} \mathrm{FeSi}_{2}$ phase and plays an important role in modifying the structure of the eutectic Si.

(3) The platelet-like $\beta$ phase is indeed the initiation point of the crack, which can be confirmed by the fracture morphology analysis. In addition, the platelet-like $\beta$-phase accelerates crack propagation. On the contrary, the fine Fe-rich particles are relatively helpful to improve the tensile strength and elongation.

(4) The melt spinning method transforms the brittle failure of Fe-rich Al-Si alloy into ductile failure, which is of great significance to the recovery and reuse of Fe-rich Al-Si alloy and has broad industrial application prospects.

Author Contributions: Conceptualization, S.L.; methodology, S.L.; validation, S.L. and X.W.; writingoriginal draft preparation, X.S.; writing-review and editing, X.H. and Z.L.; visualization, P.G. and L.Z.; software, C.C.; supervision, S.L. and X.W. All authors have read and agreed to the published version of the manuscript.

Funding: This research study was funded the Natural Science Foundation of Hebei Province (no. E2021202140), Hebei Provincial Department of Human Resources and Social Security of China (grant no. B2020005006), and Postdoctoral Innovation Fund of State Key Laboratory for Reliability and Intelligence of Electrical Equipment (EERIPD 2018003).

Institutional Review Board Statement: Not applicable.

Informed Consent Statement: Not applicable.

Data Availability Statement: The data used to support the findings of this study are available from the corresponding author upon request.

Conflicts of Interest: The authors declare no conflict of interest. We declare that we have no financial and personal relationships with other people or organizations that can inappropriately influence our work.

\section{References}

1. Zhu, X.; Blake, P.; Dou, K.; Ji, S. Strengthening die-cast Al-Mg and Al-Mg-Mn alloys with Fe as a beneficial element. Mater. Sci. Eng. A 2018, 732, 240-250. [CrossRef]

2. Puncreobutr, C.; Lee, P.D.; Karech, K.M.; Connolley, T.; Fife, J.L.; Phillion, A.B. Influence of Fe-rich intermetallics on solidification defects in Al-Si-Cu alloys. Acta Mater. 2014, 68, 42-51. [CrossRef]

3. Cameron, M.D.; John, A.T.; Arne, K.D. As-cast morphology of iron-intermetallics in Al-Si foundry alloys. Scripta Mater. 2005, 53, 955-958.

4. Terzi, S.; Taylor, J.A.; Cho, Y.H.; Salvo, L.; Suery, M.; Boller, E.; Dahle, A.K. In situ study of nucleation and growth of the irregular $\alpha$-Al $\beta$-AlFeSi eutectic by 3D synchrotron X-ray microtomography. Acta Mater. 2010, 58, 5370-5380. [CrossRef]

5. Feng, S.K.; Liotti, E.; Lui, A.; Matthew, D.; Connolley, T.; Mathiesen, R.; Patrick, S. In-situ X-ray radiography of primary Fe-rich intermetallic compound formation. Acta Mater. 2020, 196, 759-769. [CrossRef]

6. Que, Z.P.; Wang, Y.; Zhang, F. Formation of the Fe-containing intermetallic compounds during solidification of Al-5Mg-2Si-0.7Mn1.1Fe alloy. Metall. Trans. A. 2018, 49, 2173-2181. [CrossRef]

7. Gao, T.; Li, Z.Q.; Zhang, Y.X.; Qin, J.Y.; Liu, X.F. Evolution of Fe-rich phases in Mg melt and a novel method for separating Al and Fe from Al-Si-Fe alloys. Mater. Des. 2017, 134, 71-80. [CrossRef]

8. Li, X.F.; Xia, C.J.; Wu, Y.; Chen, D.; Wang, M.L.; Ma, N.H.; Wang, H.W. Effect of Er addition on the high temperature strength of Al-Si-Cu-Ni-Mg-Fe piston alloys by T5 and T6 heat treatment. Mater. Sci. 2019, 25, 376-382.

9. Wu, X.Y.; Zhang, H.R.; Zhang, F.X.; Ma, Z.; Yang, B.; Tao, T.X.; Zhang, H. Effect of cooling rate and Co content on the formation of Fe-rich intermetallics in hypoeutectic Al7Si0.3Mg alloy with 0.5\%Fe. Mater. Charact. 2018, 139, 116-124. [CrossRef]

10. Tang, Q.; Zhao, J.H.; Chen, J.; He, K. The effects of neodymium addition on the intermetallic microstructure and mechanical properties of Al-7Si-0.3Mg-0.3Fe alloys. J. Alloys Compd. 2018, 741, 161-173. [CrossRef] 
11. Zhang, J.Y.; Feng, J.; Zuo, L.J.; Ye, B.; Kong, X.Y.; Jiang, H.Y.; Ding, W.J. Effect of Sc microalloying addition on microstructure and mechanical properties of as-cast Al-12Si alloy. Mater. Sci. Eng. A 2019, 24, 138343. [CrossRef]

12. Khan, M.H.; Das, A.; Li, Z.; Kotadia, H.R. Effects of Fe, Mn, chemical grain refinement and cooling rate on the evolution of Fe intermetallics in a model 6082 Al-alloy. Intermetallics 2021, 132, 107132. [CrossRef]

13. Li, D.F.; Cui, C.X.; Wang, X.; Wang, Q.Z.; Chen, C.; Liu, S.Q. Microstructure evolution and enhanced mechanical properties of eutectic Al-Si die cast alloy by combined alloying Mg and La. Mater. Des. 2016, 90, 820-828. [CrossRef]

14. Easton, M.A.; StJohn, D.H. Improved prediction of the grain size of aluminum alloys that includes the effect of cooling rate. Mater. Sci. Eng. A 2008, 486, 8-13. [CrossRef]

15. Verma, A.; Kumar, S.; Grant, P.S.; O'Reilly, K.A.Q. Influence of cooling rate on the Fe intermetallic formation in an AA6063 Al alloy. J. Alloys Compd. 2013, 555, 274-282. [CrossRef]

16. Kilicaslan, M.F.; Altaib, S.S.; Vurdu, C.D. Effect of Ni Addition on the Morphology and Microstructure of Both Conventional Cast and Melt-Spun of Al-Si-Fe-Nb (at wt\%) Alloy. Met. Mater. Int. 2019, 25, 1457-1466. [CrossRef]

17. Rajabi, M.; Simchia, A.; Davamia, P. Microstructure and mechanical properties of Al-20Si-5Fe-2X $(X=C u, N i, C r)$ alloys produced by melt-spinning. Mater. Sci. Eng. A 2008, 492, 443-449. [CrossRef]

18. Liu, Z.T.; Wang, B.Y.; Wang, C.; Zha, M.; Liu, G.J.; Yang, Z.Z.; Wang, J.G.; Li, J.H.; Wang, H.Y. Microstructure and mechanical properties of Al-Mg-Si alloy fabricated by a short process based on sub-rapid solidification. J. Mater. Sci. Technol. 2020, 41, 178-186. [CrossRef]

19. Liu, S.Q.; Wang, X.; Cui, C.X.; Zhao, L.C.; Liu, S.J.; Chen, C. Fabrication, microstructure and refining mechanism of in situ CeB6/Al inoculant in aluminum. Mater. Des. 2015, 65, 432-437. [CrossRef]

20. Liu, S.Q.; Wang, X.; Cui, C.X.; Zhao, L.C. Enhanced grain refinement of in situ $\mathrm{CeB}_{6} / \mathrm{Al}$ composite inoculant on pure aluminum by microstructure control. J. Alloys Compd. 2017, 701, 926-934. [CrossRef]

21. Liu, S.Q.; Wang, X.; Cui, C.X.; Han, X.; Cui, C. Significantly improved particle strengthening of Al-Sc alloy by high Sc composition design and rapid solidification. Mater. Sci. Eng. A 2021, 800, 140304. [CrossRef]

22. Liu, S.Q.; Cui, C.X.; Wang, X.; Li, N.; Cui, S. Effect of cooling rate on microstructure and grain refining behavior of in situ CeB $6 / \mathrm{Al}$ composite inoculant in aluminum. Metals 2017, 7, 204. [CrossRef]

23. Han, B.H.; Liu, S.Q.; Wang, X.; Cui, C.X. Simultaneously improving strength and ductility of hybrid Al-Si matrix composite with polyphasic and multi-scale ceramic particles reinforced. Mater. Sci. Eng. A 2021, 804, 140517. [CrossRef]

24. Wu, X.F.; Wang, Z.C.; Wang, K.Y.; Zhao, R.D.; Wu, F.F. Microstructural refinement and tensile properties enhancement of Al-10Mg2Si cast alloys by copper addition. J. Alloys Compd. 2022, 896, 163058. [CrossRef]

25. Azimi, H.; Nourouzi, S.; Jamatti, R. Effects of Ti particles and T6 heat treatment on the microstructure and mechanical properties of A356 alloy fabricated by compocasting. Mater. Sci. Eng. A 2021, 818, 141443. [CrossRef]

26. Liu, T.; Pei, Z.R.; Barton, D.; Brewer, L.N. Characterization of nanostructures in a high pressure die cast Al-Si-Cu alloy. Acta Mater 2022, 224, 117500. [CrossRef]

27. Bogdanoff, T.; Lattanzi, L.; Merlin, M.; Ghassemali, E.; Jarfors, A.E.W.; Senfeddine, S. The complex interaction between microstructural features and crack evolution during cyclic testing in heat-treated Al-Si-Mg-Cu cast alloys. Mater. Sci. Eng. A 2021, 825, 141930. [CrossRef]

28. Kim, D.; Kim, J.H.; Jeon, J.Y.; Kim, Y.W.; Kobayashi, E. Local elongation of a high Fe-containing Al-Si-Cu-Mg alloy by a deformation-semisolid extrusion process. Mater. Lett. 2021, 309, 131337. [CrossRef]

29. Que, Z.P.; Mendis, C.L. Heterogeneous nucleation and phase transformation of Fe-rich intermetallic compounds in Al-Mg-Si alloys. J. Alloys Compd. 2020, 836, 155515. [CrossRef] 